\title{
Research on the Development of Agricultural Products E-commerce Based on PPP Mode
}

\author{
Junjie Li, Yijia Jing* \\ School of Management and Engineering, Zhengzhou University, Zhengzhou 450001, China \\ 1240024641@qq.com
}

Keywords: PPP mode, "Internet +", Agricultural Products E-commerce, government regulation, "Lishui mode"

Abstract: The Internet has penetrated into all aspects of social life and has become an important factor which has affected the economy, culture and personal lifestyle. E-commerce under the support of Internet technology has changed the lifestyle and consumption behavior of urban residents. Under the dual background of the government's vigorous implementation of the PPP mode and "Internet +", although agricultural products E-commerce has developed rapidly, there are still many problems. Through the analysis of the development status of agricultural products E-commerce under the PPP mode in Lishui City, Zhejiang Province, the main problems in the development of agricultural products E-commerce sales are studied, and the experience and enlightenment are summarized, and the supervision of agricultural products E-commerce based on PPP mode projects will be further explored. It will promote the development of PPP mode for agricultural products E-commerce.

\section{Introduction}

With the popularity of the Internet and the continuous growth of rural residents' income, E-commerce giants such as Ali and Jingdong have entered the rural market. In 2017, China's rural network retail sales exceeded 1.2 trillion yuan, of which online retail sales of agricultural products accounted for $20 \%$, and is expected to reach 250 billion yuan. However, due to the influence of rural geographical environment and scattered residence, the cost of rural logistics is still high, and the development of E-commerce in rural areas has encountered bottlenecks. How to solve the problems in operation is the key that E-commerce decisively solves the problem of the rural market.

The introduction of the "PPP Policy" of the Chinese government has pointed out the way for the innovation of the E-commerce mode. Refer to the list of PPP (Public Private Partnership) demonstration projects issued by the Ministry of Finance and the Social Capital Cooperation Center, the PPP projects are mainly concentrated in the fields of rail, heating, sewage and garbage disposal, and the research on the application of PPP mode in the field of agricultural products E-commerce is less (Yuan Huang, 2017). Gang Chen (2016) believes that the "PPP policy" can be applied to rural E-commerce. Zhuzhong Liu and Heying Gong (2015) proposed that "Internet +" has played a vital role in the evolution of agricultural product supply chain. Sheng Wang and Zhongbing Ding (2015) believed that government agencies as supporters could create good external environment for 
agricultural products. Although there have been extensive researches on the problems and solutions of agricultural products E-commerce, the solutions have not been implemented well, and the government as an external supporter cannot solve the problems of imperfect logistics and distribution.

Therefore, based on the development status of agricultural products E-commerce under the PPP mode in Lishui City, Zhejiang Province, this paper explores the optimization methods of agricultural products E-commerce under PPP mode. It can be used as a reference for agricultural products E-commerce in PPP mode in other regions.

\section{Research Status of Ppp Mode and Agricultural Products E-Commerce}

\subsection{The Connotation of PPP Mode}

The PPP mode was first proposed by the British government in 1982 and refers to the various partnerships established between the public and private sectors to provide public goods or services. With the sustained and rapid development of China's economy, the limited supply of infrastructure has once again highlighted the restrictive effects of economic development. The government's financial strength alone cannot meet the huge investment required for these infrastructures (Zhengxiang Zhou et al., 2015).

In the PPP management model, the participation of private enterprises is mainly to bring in project construction funds, make up for the lack of funds for the government in project construction, and make full use of social funds. Private companies usually have the expertise and skills of a certain construction field, have a talent team in the professional field, and have a more advanced management system that maximizes the benefits, which improves the efficiency of project construction (Xiaoyan Fe, 2018).

The general mode of PPP is that social capital undertakes the most of work of designing, building, operating, and maintaining infrastructure, and obtains a reasonable return on investment through "User payment” and necessary "Government payments" (Junhao Wang et al, 2016). The operation of the PPP management mode has three important characteristics, which are partnership, benefit sharing and risk sharing. The basic meaning of the PPP mode is shown in Figure 1.

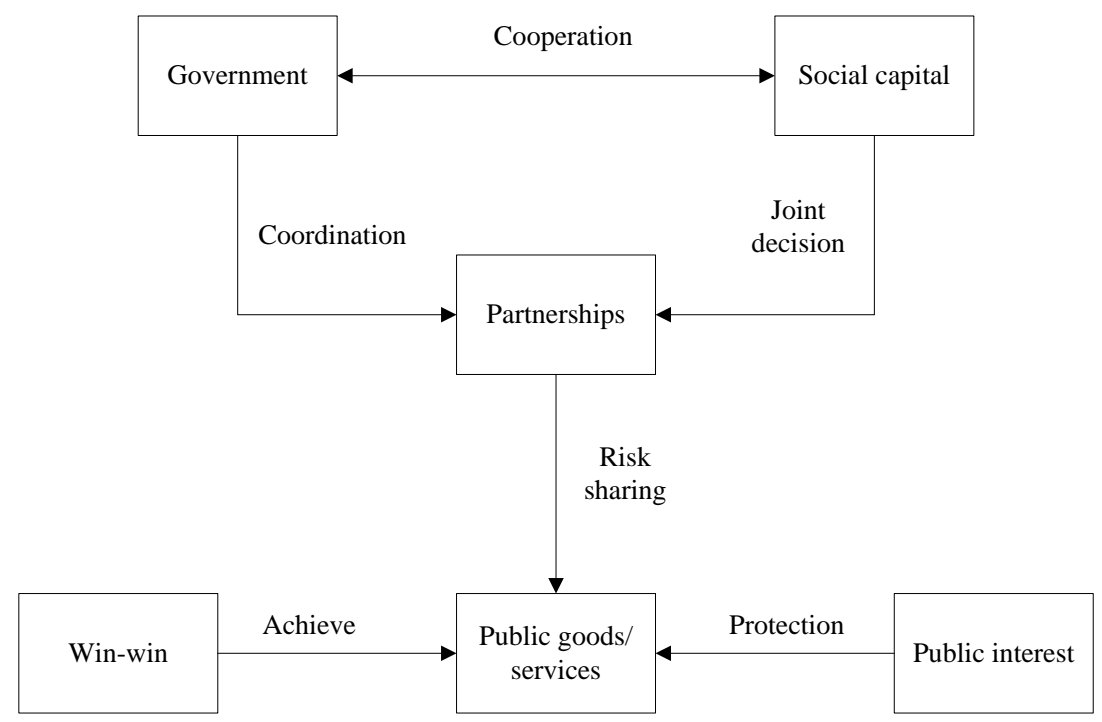

Figure 1 The connotation of the PPP mode 


\subsection{Research Status of Agricultural Products E-commerce}

Agricultural products E-commerce is the process of introducing E-commerce system into the production, processing, sales and distribution of agricultural products, collecting, integrating, transmitting and releasing information by using network information technology, and using logistics distribution system to complete the business of consumer purchase, seller sale and electronic payment of products or services online.(Yuehui Yang, 2011).

Because China's agricultural product market and E-commerce have entered a "development period", which is shown in figure 2. It is necessary to promote development and standardize supervision in the development period. In the "introduction period". Now, China's agricultural products E-commerce has entered a new stage of development, the transformation and upgrading are the main content.

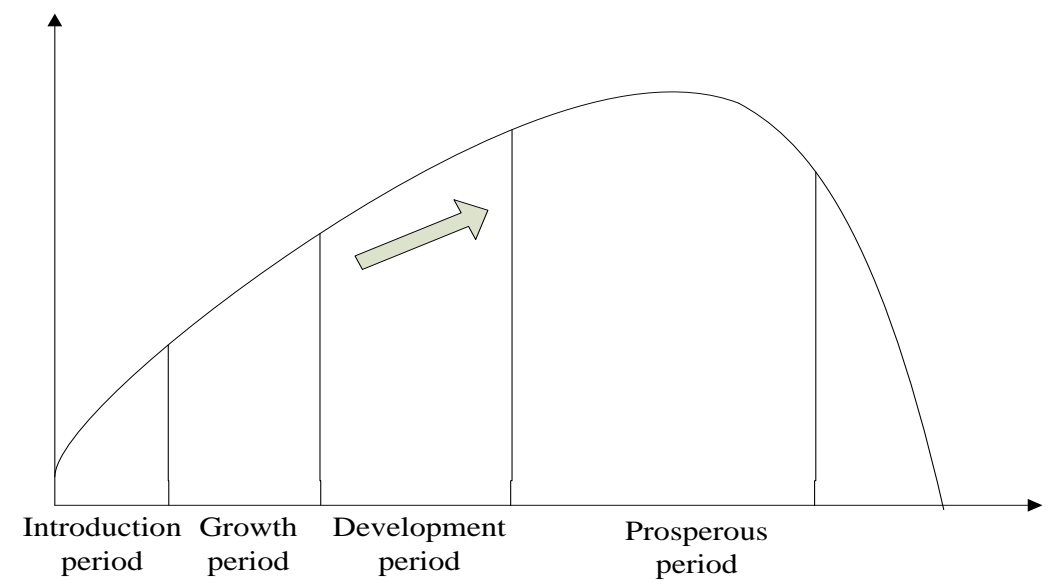

Figure 2 China's agricultural products E-commerce life cycle

The development potential of agricultural products E-commerce is large, but there are still some problems. In the subsequent development of agricultural products E-commerce, Xiaoyu Xie (2016) pointed out the importance of the development of agricultural supply chain under the Internet. Hongyu Cao (2017) pointed out that the application of the Internet can improve the logistics distribution of agricultural products in E-commerce. In addition, some scholars have proposed the significance of development in the western region. For example, Man Deng (2016) pointed out that under the background of the "Belt and Road", the development of western agricultural products in the eastern region can promote the construction of the western region, which is conducive to the implementation of the strategy of the Belt and Road.

In terms of the impact of government agencies on the agricultural products E-commerce, Jihong Ge et al. (2016) used the example of "Orange” to analyze the reengineering practice of agricultural product transportation and marketing in the Internet age. Besides, from the aspects of cost saving mechanism, long tail effect and network externaliy, Jihong Ge et al. (2016) discussed how E-commerce channels can improve the efficiency of agricultural products transportation and marketing and pointed out that the government's policy environment provides important decision-making basis for enterprises, and also provides a benign interactive network for agricultural products transportation and marketing ecosystem.

In summary, although there has been extensive research on the problems and solutions of agricultural products E-commerce, the solution has not been well implemented. In addition, the existing theory emphasizes that the government as an external supporter creates a policy environment, however, the government's identity as an external supporter cannot effectively solve the problems of imperfect end-of-sale logistics distribution system and insufficient agricultural 
product uplink. Therefore, through the use of the agricultural product E-commerce PPP mode, the government can cooperate with the enterprise to run the project as a participant, which helps it to perform its functions better and rationally use the financial expenditure to provide assistance to the agricultural E-commerce.

\section{Case Study}

As for Lishui City, the industrial chain of agricultural products of production and sales has been continuously extended, the industrial and factor agglomeration has accelerated, and the agricultural product marketing and promotion system has been continuously improved. Lishui's agricultural product E-commerce operation has formed its own unique "Lishui mode", including two different agricultural product E-commerce operation modes for the mountain mode and the street mode respectively applied to the urban and county towns.

\subsection{Mountain Mode (City)}

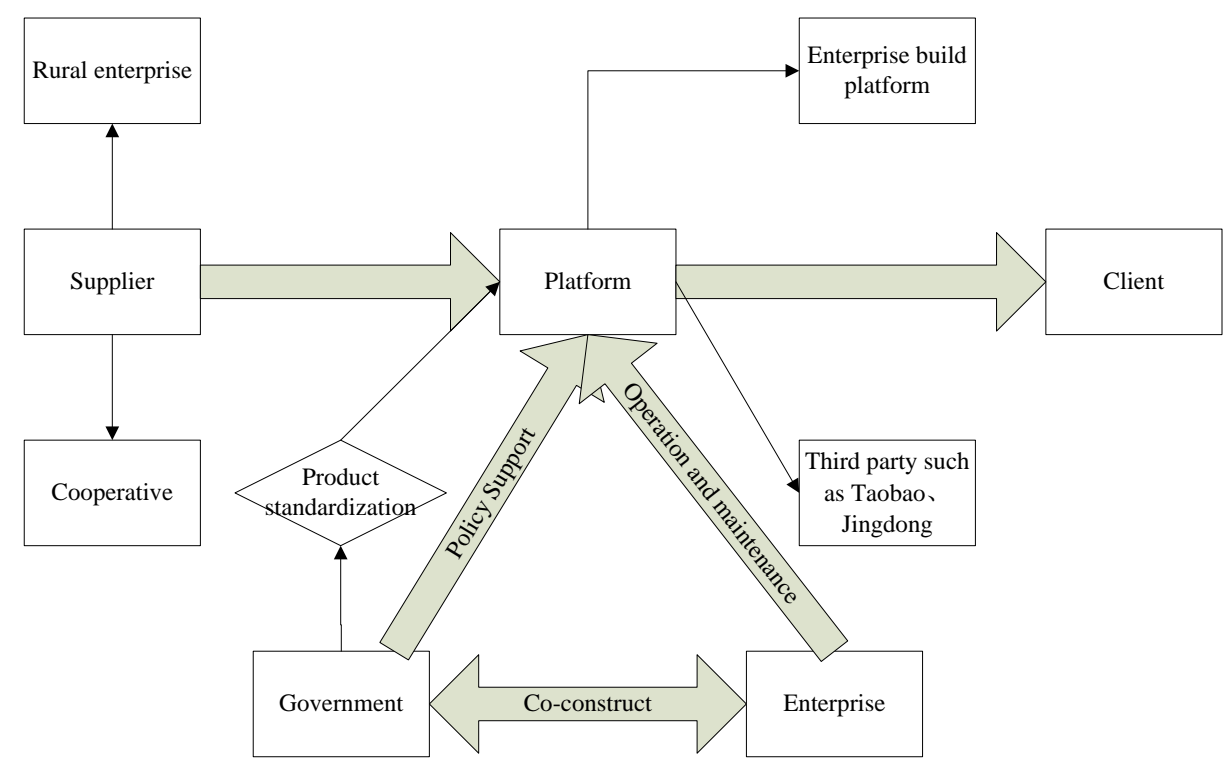

Figure 3 Mountain mode (city)

There are two modes in the construction of the E-commerce platform in mountain mode (Figure 3). The first type is that the enterprise builds its own platform. The enterprise needs funds to carry out the initial investment, and there are technologies and talents to support the follow-up operation, which is relatively suitable for the special situation of local demand.

The second is to enter third parties such as Jingdong and Taobao. Although this method has escaped the technical difficulties of building a platform, it faces the problem of how to settle in and stand out.

In the supplier side, Lishui suppliers are mainly divided into two categories: agricultural enterprises or cooperatives. The rural enterprises in Lishui are small-scale township enterprises. At the same time, these small-scale agricultural enterprises are also familiar with the local farmers. It is also convenient for the corresponding farmers to collect the agricultural products in the hands of the farmers. The mountain mode can directly obtain the corresponding products from these agricultural products companies. The cost of acquisitions and negotiations for large companies on agricultural products will be reduced.

For the government, it will not directly participate in the E-commerce of agricultural products, 
mainly through the support of policies and reward for the prize to indirectly promote the development of local agricultural products E-commerce. The government plays an extremely important and indispensable role as a leader and supporter in the entire Lishui mode, which is of great significance.

\subsection{Street Mode (Rural)}

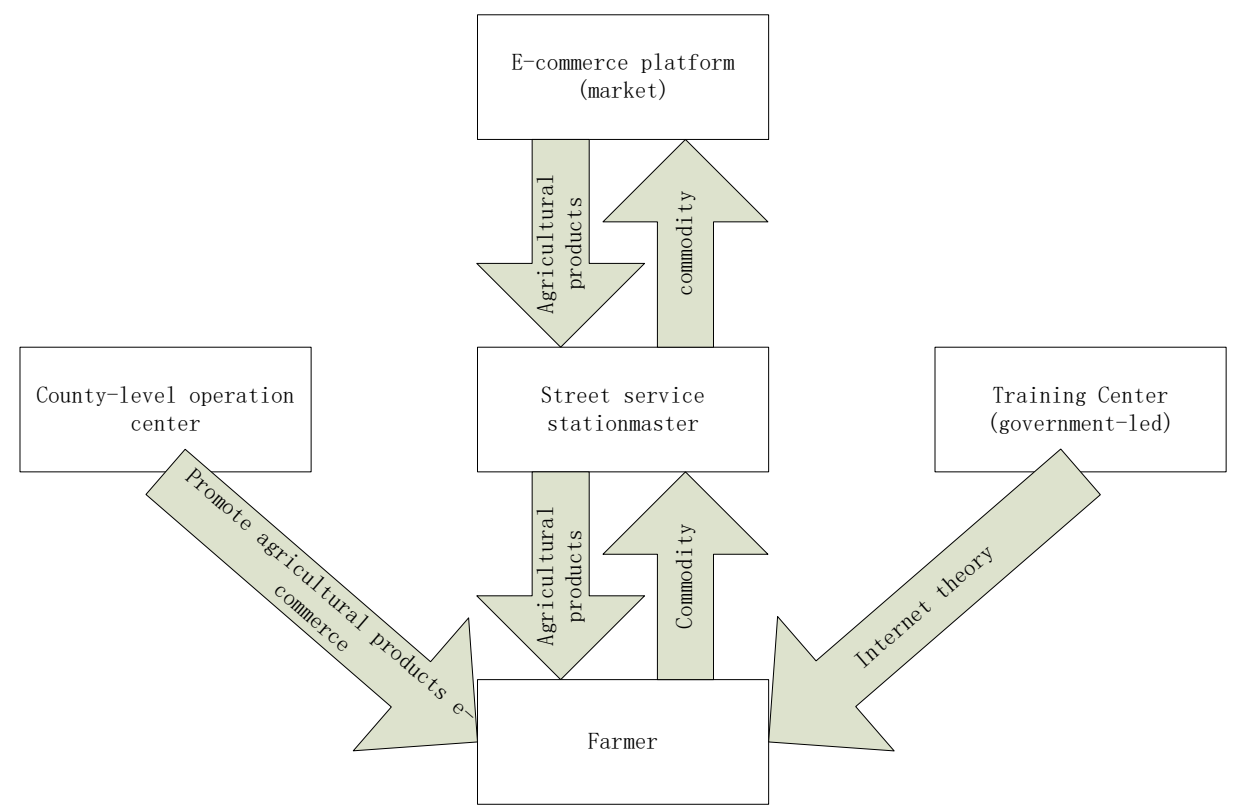

Figure 4 Street mode (rural)

The street mode adopts a combination of "a county-level operation center and government and street service stationmaster" (Figure 4). The rural market has its own particularity compared to the urban market. Due to the influence of geographical location, customs, infrastructure and other factors, rural Internet applications are difficult to spread to everyone as fast as cities, and it is impossible for everyone to actively contact the Internet E-commerce platform. Therefore, the county-level E-commerce service center is required to do an organized promotion. The supply chain management behind the agricultural products E-commerce is extremely important, and most of the farmer operators will have neglected the supply chain management links due to lack of experience.

The street mode can be promoted in many places, and it has a good demonstration role. It has played a greater role in solving the "last mile" in rural E-commerce, especially it is suitable for villages and towns where traffic is relatively occluded and it is difficult to communicate well with the outside world. The street mode has played a role in solving the shortage of talents in the development of agricultural products E-commerce in the government-led training center, and has played a role in cultivate agricultural products professionals. To sum up, the street mode is a typical way to solve the problems in the development of agricultural products in rural areas.

\section{Problems and Suggestions in the Development of Agricultural Products E-Commerce}

\subsection{Problems in the Development of Agricultural Products E-Commerce}

\subsubsection{Lack of Professional Talent}

In the process of E-commerce of agricultural products, one of the core problems is how to use the E-commerce platform to promote agricultural products. In the direction of talent shortage, 
Wenjing Hui and Chunchao Yao (2016) have studied in detail, due to the lack of specialized talents who understand agricultural products and E-commerce, Internet agricultural products E-commerce lacks information on the overall product quality. Thus the lack of cloud computing applications in the agricultural sector is difficult to accurately grasp the latest agricultural product price trends to provide accurate big data analysis.

Not only that, but the government also needs talent. Because the government supports the agricultural products E-commerce, it is necessary to have professionals in this field to deepen understanding, and help them make more scientific and effective decisions in this field. However, agricultural products E-commerce is mainly in underdeveloped areas, and the attraction to talents is low, making it difficult to retain relevant talents. The status quo eventually leads to a lack of talent.

\subsubsection{Weak Infrastructure and Unsound Logistics System}

The logistics system refers to the process of combining transportation, storage, handling, packaging, distribution processing, distribution, information processing and other functions to distribute goods from the supply to the receiving place. All aspects of the logistics system have different levels of challenges for technology. The obstacles of infrastructure are mainly due to inadequate network facilities and inadequate transportation facilities.

Taking Lishui City of Zhejiang Province as an example, the obstacles brought by logistics to the commercialization of agricultural products are mainly in three aspects. The first is the negative impact of the public transportation network on logistics. The mountain road in Lishui City is rugged, the construction of public transportation in mountain areas is imperfect, the natural geographical environment hinders the transportation of goods. The second is the problem of logistics distribution in Lishui City. The third is the lack of warehousing technology, especially in the transportation of special agricultural products. For example, fresh food is facing the problem of how to keep fresh and cold while ensuring the taste.

\subsubsection{Difficulties in Government Regulation}

Since there are few cases in which the PPP mode is applied to the E-commerce field of agricultural products, the profit model of agricultural products E-commerce projects under the PPP mode still needs to be determined. Therefore, the government still has difficulty in fund supervision, quality supervision and price supervision in the process of project development.

Furthermore, due to the lag and incompleteness of market information obtained by government departments, government departments are very essential in the supervision of project financing and capital utilization in the process of implementing PPP mode for agricultural products E-commerce. The implementation of PPP project audits in this process can ensure the profitability of investment output while maintaining investment security.

In addition, in the sales of agricultural products E-commerce, some agricultural products are directly transported from the place of origin to the location of the consumer. However, it also has food safety hazards while reducing intermediate links to improve efficiency. Therefore, it is necessary to rationally use the traceability system of agricultural products to ensure quality and safety.

\subsection{Suggestions on Agricultural Products E-Commerce Based on PPP Mode}

\subsubsection{Effectively Cultivate Relevant Talents for Agricultural Products}

When it is difficult to attract and retain talents, talent development needs to be determined according to the situation. On the one hand, it is to train farmers, and it is necessary to start from the 
basics step by step. Through the promotion of the government and practical training, it is necessary to teach them how to sell their own agricultural products through E-commerce platforms, micro-business and other ways. On the other hand, attract talents through high-paying, free office space.At the same time, the introduction of professional teams and talents, or outsourcing tasks that are highly technical and difficult to accomplish can solve the problem that talent is still insufficient.

\subsubsection{Solve Logistics and Storage Problems}

In solving the problem of logistics and warehousing, we should give full play to the important role of the government. First of all, the Lishui City Bureau of Commerce negotiated with the major logistics companies to encourage water-splitting, land concessions and other policy incentives to attract enterprises to Lishui to open logistics branches, solving the problem of logistics distribution, and greatly improving the timeliness of Lishui's overall logistics.

Secondly, the Lishui Municipal Government pays attention to the public transportation planning of urban and rural areas. It can introduce the social capital injection by adopting the PPP mode, alleviate the government's financial pressure to build the Lishui transportation infrastructure step by step, and lay a good foundation for the logistics problem of Lishui. Enterprises learn the storage of fresh food and symptomatic solution from logistics companies.

\subsubsection{Improve Incentives and Constraints}

First of all, clear institutional guarantees can effectively reduce project implementation risks and achieve effective use of the PPP mode. At the legal level, the responsibilities, obligations and risks involved in government and social capital cooperation must be determined. While protecting the interests of both parties, they should learn from each other.

Second, a sound incentive and constraint mechanism is also the key to reducing risk. A stable return on investment can attract social capital to participate. The improvement of incentives and restrictive mechanisms can promote the attention of social capital to production efficiency and quality, and enable the government to increase the focus on public interest, improve government decision-making enthusiasm, and reduce the possibility of occurrence of rent-seeking and corruption.

\section{Conclusions}

China's agricultural products E-commerce is in a period of rapid development, but there are still many problems during its operation. This paper puts forward some suggestions based on the problems existing in the PPP mode of the agricultural product E-commerce "Lishui Mode", so that the research can have implications for the development of agricultural products in other regions. In addition, the implementation of the PPP mode makes up for the shortcomings of limited government funds, and continuously exploring the regional innovation economic development mode is of great significance to the theoretical and practical research on the PPP mode of agricultural products E-commerce.

\section{References}

[1] Gang Chen, 2016. Innovation of Rural E-commerce Service and People's Livelihood Model under the "PPP Policy", Journal of Northwest A\&F University (Social Science Edition). 16(3), pp.130-135.

[2] Hongyu Cao, 2017. Innovation and Development of Agricultural Product Supply Chain under the Background of “Internet + ", Modern Business. 22, pp. 17-19.

[3] Junhao Wang, Xuanxuan Jin, 2016. Contractual Relationship between Government and Private Enterprises in PPP Mode and Its Governance---Taking China's Urban Infrastructure PPP as an Example, Journal of Economics and 
Management. 37(3), pp.62-68.

[4] Man Deng, 2016. Analysis on the Development of Agricultural Products Network Marketing in China under the Background of “One Belt, One Road”, Western Leather. 38(16),pp. 67-68.

[5] Wenjing Hui, Chunchao Yao, 2016. Research on the Development of Agricultural E-commerce in Meixian County, Shaanxi Province under "Internet + Modern Agriculture", Modern Horticulture. 24, pp.17-20.

[6] Xiaoyan Fei, 2018. Research on PPP Project Construction Partner Selection for Cross-border E-commerce Platform, E-commerce. (2), pp.35-39.

[7] Xiaoyu Xie, 2016. Research on the Status Quo and Countermeasures of Fresh Internet E-commerce in the New Mode of "Internet + Agriculture", Economist. (12), pp.169-172.

[8] Yuan Huang, 2017. Regulatory Game Analysis between Government and Agricultural Produce Producers in Agricultural E-commerce Platform under PPP Mode, SME Management and Technology (Middle). (10), pp. 35-36.

[9] Yuehui Yang, 2011. Literature Review of Agricultural Products E-commerce Research, Anhui Agricultural Sciences. 39(18), pp. 10915-10916.

[10] Zhengxiang Zhou, Xiufang Zhang, Ping Zhang, 2015. Problems and Countermeasures of PPP Mode Application under New Normal, China Soft Science. (9), pp. 82-95. 